\title{
POSTURAS HACIA LA MOVILIDAD HUMANA INTERNACIONAL CONTEMPORÁNEA EN MÉXICO. UNA EXPLORACIÓN COYUNTURAL. ${ }^{1}$
}

\section{POSTURES TOWARDS CONTEMPORARY INTERNATIONAL HUMAN MOBILITY IN MEXICO. A CONJUNCTURAL EXPLORATION.}

\author{
Carlos Mejía-Reyes ${ }^{2}$ \\ Carlos Augusto Hernández-Armas ${ }^{3}$ \\ Elsa Ortíz-Ávila ${ }^{4}$
}

\begin{tabular}{|l|l} 
Recibido: 07.03.19 & Aprobado: 28.11.19
\end{tabular}

DOI: $10.15517 /$ isucr.v20i42.41840

\section{Resumen}

El proceso de traslado de personas hacia distintos territorios en busca de mejores condiciones por razones materiales o desventuras ocasionadas por fenómenos naturales ha sido motivo de conceptualizaciones destinadas a explicar únicamente el cambio de un territorio a otro de sujetos protagonistas, dejando fuera acontecimientos que los circundan con posibilidades explicativas

\footnotetext{
${ }^{1}$ Este escrito es producto del trabajo colaborativo de la Red Internacional América Latina, África, Europa, El Caribe (ALEC) "Territorio(s), poblaciones vulnerables y políticas públicas" de la Université de Limoges, Francia, de la Red "Identidades en perspectiva multidisciplinaria" del Instituto de Investigaciones Antropológicas de la Universidad Nacional Autónoma de México y del Cuerpo Académico "Problemas Sociales de la Modernidad" de la Universidad Autónoma del Estado de Hidalgo, México

${ }^{2}$ Mexicano. Profesor Investigador de tiempo completo de la Universidad Autónoma del Estado de Hidalgo, México.Correo electrónico: carlos_mejia7563@uaeh.edu.mx ORCID: http://orcid.org/0000-0003-2998-1749

${ }^{3}$ Mexicano. Docente de tiempo parcial de la Escuela Superior de Actopan, UAEH. Correo electrónico: carlosaugustoarmas@hotmail.com ORCID: https://orcid.org/0000-0003-0988-4917

${ }^{4}$ Costarricense. Maestra en Población y Salud por la Universidad de Costa Rica. Profesora Investigadora de tiempo completo de la Universidad Autónoma del Estado de Hidalgo, México. Correo electrónico: elsa ortiz@uaeh.edu.mx ORCID: https://orcid.org/0000-0002-6016-1151
} 
holísticas; para este caso, los prejuicios negativos hacia el arribo o tránsito de agentes en movilidad así como posturas solidarias. Fenómeno que en México se caracteriza por ser espacio histórico de circulación para personas centroamericanas y caribeñas que buscan ingresar a Estados Unidos en coyuntura de agudización de barreras así como de caravanas inusitadas. Tal proceso es analizado exploratoriamente desde la Encuesta Nacional de Discriminación 2017 destinada a visibilizar posturas y creencias al respecto, analizado con técnicas multifactoriales de asociación y comparativamente entre entidades federativas a partir de su vecindad con las fronteras.

Palabras claves: Movilidad humana; migración; actitudes; Centroamérica-Caribe; México.

\begin{abstract}
The process of transferring people to different territories in search of better conditions for material reasons or misadventures caused by natural phenomena has been a reason for conceptualizations aimed at explaining only the change from one territory to another of protagonists, leaving out events that surround them with holistic explanatory possibilities; in this case, the negative prejudices towards the arrival or transit of agents in mobility as well as solidarity positions. Phenomenon that in Mexico is characterized by being a historical circulation space for Central American and Caribbean people who seek to enter the United States at a time of sharpening barriers as well as unusual caravans. This process is explored exploratoryly from the 2017 National Discrimination Survey aimed at making visible positions and beliefs in this regard, analyzed with multifactorial association techniques and comparatively between federative entities based on their neighborhood with the borders.
\end{abstract}

Key words: Human mobility; migration; attitudes; Centroámerica-Caribe; México.

Introducción

Según el Informe sobre las Migraciones en el Mundo (2018) en 2015 el 3.3\% de la población mundial se encuentra en situación de migrante internacional, lo que es igual a 244 millones de personas; $0.7 \%$ más de lo estimado hace casi veinte años. De estos, el $24.5 \%$ son personas desplazadas o refugiadas y se calcula que para 2050 la cantidad será de 405 millones. Ante estas circunstancias los organismos internacionales y estados miembros han decidido, en 2016, afrontar los retos inherentes del tema. Así la Asamblea General de las Naciones Unidas 
emitió la Declaración de Nueva York para los Refugiados y Migrantes (2016) que atiende el respeto de los derechos humanos de personas refugiadas y migrantes, garantizar que los y las menores en esa condición estudien en el país de recepción a los seis meses de su llegada, prevenir la violencia de género, prestar apoyo a países receptores de grandes poblaciones, combatir la xenofobia, encontrar viviendas para sectores que necesiten reasentamiento, reforzar su contribución al desarrollo económico y social del país de acogida, entre otras medidas.

A nivel América Latina, países como Costa Rica, Honduras, El Salvador, Guatemala, Panamá y México lo aplicaron -en un ejercicio considerado piloto- con el Marco Regional Integral de Protección y Soluciones (CRPSF, por las siglas en inglés). Sin embargo se enfatizó el tema de personas refugiadas en el que México adoptó medidas de capacitación, empleo y servicios financieros (UN Refugee Agency, 2017). Aunque en 2018 se ratificó el ejercicio de cooperación con respecto a la migración en general (CEPAL, 10 de diciembre de 2018).

La definición del fenómeno de la que parten estos organismos internacionales supone el concepto elemental de migración congruente al de sociología y ciencias sociales que se entiende como el traslado de habitantes de un espacio, domicilio o país a otro (Rama, 1979; Gallino, 1995; Barfield, 2000; Dudley, 2006; Kritz, 2007; Crowder y Hall, 2007). En el mismo sentido disciplinas como geografía (López, Fernándes, Sposito y Trinca, 2015), psicología (Galimberti, 2002) y economía (Hasse, Schneider y Weigelt, 2004) lo conceptualizan; aportando un nivel de comprensión del proceso estrictamente espacial y por tanto descriptivo (Alonso, 2019).

Empero, recientemente la academia ha puesto en tela de juicio el término a causa de la limitación al plano territorial del movimiento de grupos y ha recuperado conceptos como movilidad (Alonso, 2019) basado en postulados de Alain Tarrius (2000) cuyas conjeturas señalan que el cambio de espacio traen consigo también transformaciones de jerarquías sociales, prestigios, apropiación territorial, nuevos hábitos y por supuesto de identidades circulatorias: la llamada tercera nación (no pertenecer ya al lugar de origen ni al de arribo, sino a ambos); de forma que "la connotación de las movilidades en términos de inmigración o de emigración aporta muy poco a esta comprensión y oscurece particularmente con una carga ideológica (p. 48)”. 
Este término, a diferencia de "migración", implica dinamismo no solamente entre espacios físicos, sino de condiciones culturales y posiciones sociales, redimensionando la perspectiva comprensiva del fenómeno (Alonso, 2019). También desde la postura sociológica contemporánea de Michel Maffesoli (2005) el proceso de traslado de personas de un territorio a otro con fines aspiracionales materiales y culturales lo ha denominado "movilidad social o desplazamiento" (P. 29). Con esta lectura y con bases epistemológicas de su propuesta teórica general, en el que la proxémia, afinidad y experiencias subjetivas toman relevancia, hacen que el término de “migración” sea limitado para comprenderlo holísticamente (Alonso, 2019).

De forma que la migración, inmigración, transmigración y emigración solo son algunas dimensiones del fenómeno de movilidad. Por ello es menester contemplar escenarios de salida, tránsito y llegada en relación con procesos de transformación en la etapa globalizadora neoliberal, estudiar las alteraciones en la identidad y sensaciones de seguridad en los trayectos, el multifactorial entramado del mercado de trabajo capitalista no como consecuencia sino como parte integral de la movilidad y las circunstancias del país de origen que la influye, formas causadas por estructuras macro así como también de acciones de grupos inmiscuidos (migrantes y no migrantes) en dimensión local-global, experiencias de las personas que transitan de forma legal o ilegal (Alonso, 2019) así como percepciones de las personas adscritas al territorio o cultura que los reciben temporal o permanentemente; tal y suficientes trabajos científicos han referido (Bauman, 2016; Beck, 2007; Thomas y Znaniecki, 2006; Navarrete, 2016; Polanyi, 2007; Wimmer, 1997; Willems, 1995; Semyonov, Raijman, Yom y Schmidt, 2004; Markaki y Longhi, 2013; Meseguer y Maldonado, 2015; Kevins y Lightman, 2019; Semyonov y Raijman, 2006; Ceubanu y Escandell, 2010; Brenner y Fertig, 2006; Kevins y Lightman, 2019; Solé, 2010; Kunovich, 2004; Quillian, 1995). En suma, el proceso de movilidad epistemológicamente implica analizar procesos entrecruzados y multidimensionales.

Para el caso de la exploración contemporánea de la movilidad centroamericana hacia México implica reconstruir un esbozo panorámico del proceso para posteriormente aproximarse a la diversidad de factores macro y micro que la explican en sus etapas pragmáticas; pero también analizar las percepciones coexistentes desde agentes en distintas posiciones del proceso. 
Antecedentes

La movilidad de agentes centroamericanos(as) hacia México se explica en tres etapas. La primera en 1882 con la firma del tratado de límites entre Guatemala y México. En ese contexto el traslado de personas a través de la instituida frontera se mantuvo a causa de lazos familiares, comunitarios y laborales. La segunda se debió a la explotación de recursos naturales en territorio mexicano, región de Soconusco (Chiapas), por parte de capital alemán, generando mercados de trabajo y movimientos de mano de obra guatemalteca hacia el espacio laboral incipiente. Las personas trasladaron su vida a México por las aún redes vigentes. Aunado a que la mano de obra mexicana era escasa, las fincas utilizaron mecanismos fraudulentos para atraer personas desde Guatemala. Así hasta que los niveles de trabajadores extranjeros rebasaron a los locales. El tercer momento fue a inicios del siglo XX por el traslado de trabajadores temporales guatemaltecos para el cultivo de café, pero ahora sin limitantes legales o permisos. Incluso como parte de la vida fronteriza no se consideraban como extranjeros por lo que la tensión, extrañamiento o antagonismo era inexistente (Castillo y Toussaint, 2015).

Fue hasta la década de los ochenta que por las crisis económicas, políticas y conflictos armados en Guatemala, Nicaragua y El Salvador que propiciaron desplazamientos de personas hacia México, Estados Unidos y Canadá en estatus regulares pero la gran mayoría de manera ilegal. Las repuestas de la población receptora fue de apoyo pero no así, inicialmente, de las autoridades migratorias mexicanas; hasta años después con la intervención diplomática y económica de las Naciones Unidas con la postulación de acuerdos para recibir refugiados. En la década siguiente se retiró la ayuda de fondos financieros y comenzó a organizarse el retorno voluntario o regularización de estancia a través de residencia o naturalización; dando como resultado la adscripción de aproximadamente veinticuatro mil personas de origen guatemalteco. Esto en el contexto de insurrección armada en Chiapas del Ejército Zapatista de Liberación Nacional, donde las autoridades acusaron a la intromisión de refugiados guerrilleros en el surgimiento del movimiento, agudizándose por ello controles fronterizos. Aunado a lo anterior, las personas que regresaban a los territorios centroamericanos encontraron un país en absoluta crisis, por lo que sus opción fue la desplazamiento al exterior; pero ahora a Estados Unidos (E.U.A.), Canadá (Castillo y Toussaint, 
2015) o hacia Costa Rica y Panamá (Canales y Rojas, 2018) y recientemente a México como destino final (Organización Internacional para las Migraciones, 2018).

Sin embargo, aún es E.U.A el principal receptor porque hasta 2015, el 97\% de mexicanos en movilidad residen en ese país, mientras que $78 \%$ del total son centroamericanos(as) (Organización Internacional para las migraciones, 2018). Pero en 2014 se asegura que por primera vez en la historia, la cantidad de personas centroamericanas superaron considerablemente a los(as) mexicanos (Centro de Estudios Internacionales Gilberto Bosques, 2015) y en 2017 se afirma que el número de mexicanos(as) indocumentadas(os) en aquel país dejó de ser mayoría (Passel y Cohn, 12 junio 2019; González-Barrera y Krogstad, 28 junio 2019). Lo que tienen relación con que poco más del $12 \%$ de la población centroamericana vive en Estados Unidos y el país con mayor porcentaje de residentes fuera es El Salvador con 27.14\% (Sandoval, 2015).

Para dimensionar el fenómeno, la cantidad de personas indocumentadas en movilidad por México que provienen de Centroamérica entre 1990 a 2005 fue de 390000 a 430000 por año. De 2006 a 2009 se redujo 70\%, de modo que el flujo fue de 170000 anualmente, pero entre 2010 y 2011 creció 40\%, es decir aproximadamente 300000 personas; manteniendo ese ritmo hasta 2014 (Schiavon, 2015). En 2017 México se posicionó como el segundo país -solo por debajo de la Indiacon mayor número de inmigrantes en su territorio (trece millones de personas) y primer país corredor o de tránsito (United Nations, Departament of Economic and Social Affairs, Population Division, 2017; Consejo Nacional de Población, Fundación BBVA Bancomer y BBVA Research, 2017).

En mayo y junio de 2016 hubo un flujo migratorio extraordinario proveniente de distintos territorios para asentarse en Tijuana con el objetivo de solicitar asilo en Estados Unidos. La procedencia de estas personas fue de Eritrea, Ghana, Armenia, Nueva Guinea, Ucrania y otros quince países; pero predominaron de Haití (París, 2018). El caso de estos últimos, la particular motivación de movilidad data de 2010 a causa de un terremoto que devastó la isla. Brasil acogió a aquellos que pudieron salir para contratarlos temporalmente y levantar la infraestructura de los juegos olímpicos de 2012 y algunos otros accedieron a Estados Unidos por un programa de protección temporal. Pero Brasil de 2016 estaba en crisis económica y política, lo que mermó las 
posibilidades de empleo y provocó la movilidad hacia el norte del continente en busca de incorporarse como sus compatriotas seis años atrás (Montoya-Ortíz y Sandoval-Forero, 2018; París, 2018b)

En 2018 la visibilidad de la movilidad por México fue mediáticamente importante, más allá del carácter cuantitativo, ya que el 19 de octubre una caravana de miles de personas centroamericanas arribaron a la frontera con la intención de trasladarse a Estados Unidos de América (González, 26 mayo 2019). Por más de tres semanas caminaron por el territorio nacional hasta el 13 de noviembre que arribaron a Tijuana. El 25 del mismo mes intentaron cruzar, pero fueron repelidos por la policía fronteriza estadounidense. Solamente lograron ingresar dos mil personas y el resto, aproximadamente dos mil más, permanecen en aquella ciudad fronteriza hasta enero de 2019 (Alonso, 2019).

Durante este proceso, las reacciones de la población mexicana se polarizaron entre Solidaridad y empatía por un lado (Redacción AN, 24 octubre de 2018; MartínezHernández-Mejía, 2019), xenofobia y racismo por otro (Villamil, 22 octubre 2018; Tourliere, 18 de noviembre de 2018).

Sin embargo, estas expresiones solidarias y hostiles no son exclusivas de la coyuntura, sino que se hicieron más visibles por la cobertura mediática, ya que esta población experimenta sistemáticamente criminalización (Márquez, 2015) al grado que fue hasta 2011 que dejó de ser considerada la "migración ilegal” como delito (Gall, 2018). También son víctimas constantes de traficantes de personas (García, 2017), extorsión, corrupción y reclutados(as) en organizaciones delictivas (Izcara, 2016). Situación que se agrava cuando se trata de mujeres ya que la violencia sexual es un fenómeno periódico disfrazado de "intercambio" con varones desconocidos en la misma situación por favores de protección (Willers, 2016). De forma extrema el riesgo es la muerte en condiciones de violencia, como lo sucedido en San Fernando, Tamaulipas, 2010, cuando fueron encontrados setenta y dos cuerpos con signos de tortura de migrantes centro y sudamericanos; de los cuales catorce eran de mujeres, el resto varones. En ese mismo año se documentaron 214 secuestros con resultado de 11333 víctimas. Además, se calculan 20000 raptos al año (Garibo, 2016). 
Ante este escenario, diversas agrupaciones palian los riesgos con refugios de acogida temporal, apoyo alimentario en el proceso como el caso de "Las Patronas", también colectivos antirracistas distribuidos por las rutas que ofrecen refugio y procuran protección a los derechos de las y los migrantes. El común denominador de estos apoyos es que son creados por agentes no en movilidad, sino de personas oriundas del territorio de paso. Pero también existen los activismos encabezados por las y los protagonistas como el Movimiento Migrante Mesoamericano (MMM), cuya apuesta es incidir en las esferas de toma de decisiones mexicanas que impacten en reformas migratorias entre los países involucrados así como en la cotidianidad de las personas en traslado. De igual forma colaboran denunciando violaciones a los derechos humanos, así como con casas de resguardo (Varela, 2016). Hasta 2018 se registran, oficialmente en la Organización Internacional de Migración, más de cien casas y albergues (Organización Internacional para las Migraciones/OIM México, 2018).

Las razones de las expresiones hostiles contra migrantes externos se explican a partir de dos tradiciones científicas (Markaki y Longhi, 2013) o razones sociales (Bauman, 2016). La primera por constructos culturales de definición colectiva identitaria del "nosotros" frente a la otredad como referente delimitante, el cual implica jerarquías clasificatorias del primer sobre el segundo constructo (Markaki y Longhi, 2013). La definición de la distancia clasificatoria se realiza mediante la conformación de denominaciones lingüísticas basadas en estereotipos (Fuentes y Márquez, 2006) para su ubicación puntual de extrañeidad o externalidad de consecuencias cognitivas, afectivas y actitudinales defensivas ante la amenaza de la proximidad (Beck, 2007) y por ser "aterradoramente impredecibles" (Bauman, 2016, p. 15). Este esquema en México fue asentado con el mito fundacional de nación cuya naturaleza sustenta recelo, desconfianza y sentimiento de amenaza contra extranjeros(as) a causas de constructos narrativos basados en procesos históricos como la "invasión” europea que implicó genocidio y saqueo; enseguida el colonialismo opresor y por último las revueltas independentistas y revolucionarias que postularon como motivante el mestizaje así como la herencia indígena con fines autodefinitorios (Rebolledo, 2017). En imaginarios colectivos, educación pública y legislaciones la hostilidad a extranjeros(as) fue evidente -a pesar de que el porcentaje de externos nuca rebasó el uno por ciento- al grado que hasta 2011 dejó de ser sancionada la inmigración ilegal con cárcel (Gall, 2018). 
La segunda explicación radica en la competencia por el mercado de trabajo (Markaki y Longhi, 2013) donde los agentes se comprenden hostiles a los y las personas en movilidad a partir del cálculo costo-beneficio con respecto a la escases bienes materiales, puestos de trabajo y distribución del ingreso. Puntualmente se ha referido una correlación que apunta hacia una aceptación de nuevos integrantes del extranjero en el país si este es desarrollado mientras que se orienta hacia la exclusión cuando se trata de países en desarrollo (Meseguer y Maldonado, 2015). Sin embargo ambas posturas coexisten empíricamente en el proceso y contexto mismo de la consideración social hacia personas en movilidad (Bauman, 2016; Wimmer, 1997). Pero las condiciones contemporáneas de México en cuanto el mercado laboral son definitivamente desventajosas incluso para sus propios connacionales ya que solamente el $40 \%$ del mercado laboral es formal, 55\% es informal, el resto es desempleo (Mejía, Blancas y Galindo, 2019); lo que define al contexto como poco favorable, según las teorías, para la aceptación de movilidad humana externa.

Con estos elementos el objetivo del estudio es construir una aproximación a las posturas de informantes mexicanos(as) sobre el papel gubernamental frente a la movilidad y ubicar las categorías de variables asociadas a ellas. También es comparar los juicios que en las entidades federativas se emiten con una lectura segmentada entre territorios fronterizos y no limítrofes con otros países.

Materiales y métodos

Para ello se hace uso de la segunda Encuesta Nacional de Discriminación 2017, elaborada por el Instituto Nacional de Estadística y Geografía (INEGI) y el Consejo Nacional para Prevenir la Discriminación (CONAPRED), aplicada a 39101 viviendas con la metodología muestral aleatoria, poliepática, estratificada, por conglomerados encuestando a 102245 personas. Su objetivo es captar actitudes, prejuicios, opiniones hacia distintos grupos discriminados por diversos motivos, así como también identificar experiencias de discriminación en distintos ámbitos (Consejo Nacional para Prevenir la discriminación e Instituto Nacional de Estadística y Geografía, 2017) 
La unidad de observación de la muestra correspondiente a la variable dependiente está compuesto por un informante por hogar de 15 años o más, de forma que la cantidad de agentes de la muestra a observar es de 35261 casos. Las características de esta es $44.9 \%$ son varones y $55.1 \%$ mujeres. La media de edad es de 44.7 años con desviación estándar de 17.2. En cuanto a la escolaridad el 5.5\% de informantes no tiene educación algina, el $25.8 \%$ solo tiene estudios de primaria, $26 \%$ con secundaria, $22.3 \%$ con formación media superior en sus distintas modalidades, $18.5 \%$ con licenciatura y $1.9 \%$ con posgrado. Con respecto al estatus marital el $17.2 \%$ se encuentra en unión libre, $9.2 \%$ separado, $3.5 \%$ divorciado(a), $43 \%$ casada(o), en viudez el $8.3 \%$ y soltería el 18.7\%. El 57.2\% tiene un trabajo, $24.1 \%$ se ocupa como principal actividad el hogar, el $4.5 \%$ no trabaja, $6.3 \%$ es pensionado o jubilado y $3.3 \%$ es estudiante.

Como variable dependiente se utiliza la numerada como po3_3 y que versa sobre las opiniones de mexicanos(as) sobre distintas acciones que el gobierno debiera tomar con respecto a las personas que ingresan al país por razones de riesgo en sus lugares de origen: "Respecto a las personas centroamericanas y de otros países que llegan a México por violencia o desastres naturales ¿El gobierno debería...”. Las opciones de respuestas son: 1) "Ubicarlos en un refugio hasta que puedan regresar" 2) "Darles papeles para que vivan y trabajen aquí" 3) "Cerrarles la frontera" 4) "Regresarlos a su país" y 5) "otra". Con esta se buscará observar la posturas precisas o actitudes de exclusión o solidaridad frente a externos. Es importante señalar que esta variable fue respondida por el total de la muestra.

Como variables independientes el estudio contempla las de control básicas iniciando con el sexo. Esta ha sido utilizada recurrentemente en investigaciones empíricas sobre la temática de la xenofobia en Europa contra "migrantes" (Willems, 1995) como para estudios mexicanos en casos de actitudes contra personas en movilidad interna (Laborín, Parra y Valdéz, 2012) así como de extranjeros(as) en el país (Meseguer y Maldonado, 2015); conformándose como una variable explicativa indispensable. La tendencia se inclina a subrayar que son los varones quienes exhiben actitudes de menor aceptación hacia estos sectores poblacionales. 
La edad es otra que originalmente fue construida como variable continua, pero en este estudio fue recodificada en diez rangos tomando como criterio los parámetros oficiales de minoría de edad (hasta 17 años), jóvenes (18 a 25, 26 a 30), adultos (31 a 35, 36 a 40, 41 a 45, 46 a 50, 51 a 55, 56 a 60) y adultos mayores (60 años o más). Antecedentes de ésta como influyente en actitudes ante personas foráneas se localizan ejercicios internacionales que refieren a la edad como un factor clave de explicación (Willems, 1995; Semyonov, Raijman, Yom y Schmidt, 2004) y lo mismo para el caso local (Meseguer y Maldonado, 2015). Los resultados coinciden en señalar a informantes de edades adultas como más propensas a la intolerancia hacia personas externas.

El nivel de escolaridad opera también entre los antecedentes empíricos de su utilización para este tipo de aproximaciones en indagaciones internacionales (Willems, 1995; Semyonov, et.al, 2004) como nacionales (Meseguer y Maldonado, 2015). Así la variable contiene nueve dimensiones: sin escolaridad, preescolar, primaria, secundaria, normal básica, carrera técnica o secundaria técnica, preparatoria o bachillerato, carrera técnica con preparatoria, licenciatura, maestría o doctorado. Las tendencias apuntan a señalar que entre menor escolaridad menor aceptación de externos(as) (Zamora-Kapoor, Kovincic y Causey, 2013).

La variable estado civil está conformada por las categorías: unión libre, separado(a), divorciado(a), viudo(a), casado(a) y soltero(a). De igual manera es un predictor recurrente en análisis aplicados europeos (Kevins y Lightman, 2019; Semyonov y Raijman, 2006) cuya tendencia en revisiones anteriores apunta hacia informantes en núcleos familiares constituidos donde se localizan opiniones de prejuicios negativos contra foráneos de otros países en general (Ceubanu y Escandell, 2010; Brenner y Fertig, 2006)

El estrato económico conforma una variable altamente influyente para explicar las actitudes o posiciones respecto a las personas en movilidad en estudios europeos en particular. Se ha comprobado que en coyunturas de crisis económicas el total de informantes, sin importar el estrato, contemplan a la inmigración como riesgosa para las certezas materiales en general (Quillian, 1995). Pero de forma recurrente se refiere una relación que indica entre más baja es la clase social mayores son las actitudes de rechazo (Solé, 2010; Kunovich, 2004). Para este estudio la variable está conformada por cuatro categorías: Alta, media alta, media baja y baja. 
La situación de empleo resulta también una variable que suele ser utilizada en este tipo de estudios, ya que como se ha argumentado, la relación de prejuicio negativo contra sujetos externos obedece a la competencia por espacios en el mercado laboral (Markaki y Longhi, 2013; Meseguer y Maldonado, 2015). La variable se compone de ocho categorías: Trabajó (Al menos una hora), tenía trabajo pero no trabajó, buscó trabajo, es jubilado o pensionado, estudiante, hogar y cuidado de hijos, impedido para trabajar y no trabaja.

Como última se contempla a la religión, ya que como se ha teorizado contemporáneamente se afirma, con evidencia empírica, que es en personas religiosas donde se concentran actitudes de empatía por otros(as) en circunstancias adversas de movilidad además de hacer contrapeso frente a actitudes discriminatorias en Estados Unidos (Portes, 2006). También se documenta que estos grupos religiosos, particularmente católicos, coadyuvan a su integración social y las relaciones interculturales (Sánchez y Ortega, 2013). En territorio mexicano se documentó que iglesias protestantes fungieron como soportes importantes para las movilidades de centroamericanos hacia Chiapas en los albores del siglo XX (García, Basail y Villafuerte, 2008). En suma se ha teorizado acerca de su papel como generador de vínculos sociales y apoyo a su arribo (Odgers, 2005). La variable se constituye a partir de siete categorías: católica, cristiana, T. De Jeová, Pentecostal o pentecostés, otra, no tiene religión y no sabe.

El procedimiento de análisis inicial es estadístico descriptivo a partir de la comparación de la variable dependiente con las submuestras de treinta y dos entidades federativas. Con ello contrastamos fenómenos sociales de la misma clase en diferentes escenarios para extraer semejanzas o diferencias que permitan deducir particularidades (Sartori, 1970; Colino, 2009; Mills, Van de Bunt y De bruijn, 2006). Para ello se ponderará la muestra con el factor de expansión a nivel persona para ajustar las frecuencias por sexo, es decir que la muestra tiene una distribución porcentual de $44.9 \%$ de hombres encuestados y de $55.1 \%$ mujeres, con la ponderación se ajusta a niveles de $47.3 \%$ y $52.7 \%$ respectivamente.

Posteriormente, la técnica de análisis multivariada a considerarse prescinde de modelo de regresión para describir las relaciones entre variables, ya que como la independiente es cualitativa categórica, el coeficiente de determinación del modelo (pseudo $\mathrm{R}^{2}$ ) regularmente es 
significativamente inferior a uno (Gujarati y Porter, 2010), no permitiendo clarificar una estimación más precisa de las múltiples influencias entre categorías. De manera que el Análisis de Correspondencias Múltiples (ACM) tiene por objetivo atender la vinculación entre categorías (Batista y Sureda, 1987) a partir de su colocación o distribución en cualquiera de los cuatro sectores de los planos vectoriales (Greenacre y Hastie, 1987; Visauta y Martori, 2003) proporcionando una medida conjunta de asociación: Alfa de Crobach (Sourial, et.al, 2006).

\section{Resultados}

El porcentaje de la muestra nacional que refirió el gobierno debiera ubicar a migrantes en un refugio hasta que puedan regresar es de 53.3\%, mientras quienes opinan que se debiera otorgarles documentos para vivir y trabajar en México es de 33.3\%. El 12\% opinó se debieran regresar a su país y solamente el $1 \%$ señaló cerrarles la frontera; el resto 0.3 refirió otras alternativas que no se detallan (Cuadro 1).

Cuadro 1. Distribución porcentual de opiniones hacia personas en movilidad en México según entidad federativa.

\begin{tabular}{lclccc}
\hline & $\begin{array}{c}\text { Ubicarlos } \\
\text { en } \\
\text { refugios } \\
\text { hasta que } \\
\text { puedan } \\
\text { regresar }\end{array}$ & $\begin{array}{l}\text { Darles } \\
\text { papeles para } \\
\text { que vivan y } \\
\text { trabajen } \\
\text { aquí }\end{array}$ & $\begin{array}{c}\text { Cerrarles } \\
\text { la frontera }\end{array}$ & $\begin{array}{c}\text { Regresarlos } \\
\text { a su país }\end{array}$ & Otra \\
\hline Aguascalientes & 53.0 & 36.3 & 0.5 & 10.2 & 0.0 \\
\hline $\begin{array}{l}\text { Baja } \\
\text { California }\end{array}$ & 38.8 & 56.4 & 0.0 & 4.1 & 0.6 \\
\hline $\begin{array}{l}\text { Baja } \\
\text { California Sur }\end{array}$ & 54.8 & 26.1 & 0.2 & 17.8 & 1.0 \\
\hline Campeche & 42.4 & 37.3 & 1.5 & 17.6 & 1.2 \\
\hline Coahuila & 38.6 & 48.9 & 0.5 & 11.6 & 0.4 \\
\hline Colima & 62.8 & 29.4 & 0.8 & 7.0 & 0.1 \\
\hline Chiapas & 69.0 & 14.9 & 1.9 & 13.7 & 0.4 \\
\hline Chihuahua & 50.8 & 35.3 & 0.4 & 13.5 & 0.0 \\
\hline Ciudad de & & & & & \\
México & 58.4 & 30.9 & 0.8 & 9.6 & 0.3 \\
\hline Durango & 57.1 & 34.7 & 0.0 & 7.9 & 0.2 \\
\hline
\end{tabular}




\begin{tabular}{lccccc}
\hline Guanajuato & 50.6 & 37.4 & 1.6 & 10.2 & 0.2 \\
\hline Guerrero & 63.4 & 25.4 & 0.9 & 10.1 & 0.2 \\
\hline Hidalgo & 49.5 & 32.2 & 0.8 & 17.0 & 0.4 \\
\hline Jalisco & 48.4 & 39.9 & 0.5 & 11.6 & 0.2 \\
\hline México & 55.1 & 30.7 & 2.5 & 11.3 & 0.4 \\
\hline Michoacán & 55.0 & 31.9 & 0.6 & 11.8 & 0.6 \\
\hline Morelos & 66.7 & 26.9 & 0.6 & 5.4 & 0.4 \\
\hline Nayarit & 55.6 & 30.2 & 0.3 & 13.8 & 0.1 \\
\hline Nuevo León & 49.7 & 36.6 & 0.9 & 12.5 & 0.2 \\
\hline Oaxaca & 62.3 & 18.5 & 1.1 & 17.8 & 0.2 \\
\hline Puebla & 51.6 & 33.1 & 0.8 & 14.3 & 0.2 \\
\hline Querétaro & 45.3 & 45.5 & 0.1 & 8.9 & 0.1 \\
\hline Quintana Roo & 52.2 & 37.0 & 1.5 & 9.1 & 0.2 \\
\hline San Luis & & & & & \\
Potosí & 54.3 & 34.6 & 0.2 & 10.8 & 0.1 \\
\hline Sinaloa & 53.3 & 34.3 & 1.3 & 10.9 & 0.2 \\
\hline Sonora & 52.6 & 34.5 & 0.1 & 12.6 & 0.2 \\
\hline Tabasco & 51.0 & 32.2 & 1.3 & 16.4 & 0.1 \\
\hline Tamaulipas & 52.5 & 37.8 & 0.1 & 8.7 & 0.9 \\
\hline Tlaxcala & 60.1 & 25.5 & 0.6 & 13.2 & 0.6 \\
\hline Veracruz & 48.6 & 33.9 & 0.7 & 16.6 & 0.1 \\
\hline Yucatán & 52.0 & 29.3 & 0.8 & 17.0 & 0.9 \\
\hline Zacatecas & 48.8 & 35.7 & 0.6 & 14.4 & 0.5 \\
\hline Promedio & & & & & \\
nacional & 53.3 & 33.3 & 1.0 & 12.0 & 0.3 \\
\hline Fune: Elabo & propis
\end{tabular}

Fuente: Elaboración propia con base en Encuesta Nacional sobre Discriminación 2017.

Comparativamente a nivel de sub-muestras por entidades federativas, en 30 de 32 predomina porcentualmente la primera opción (Refugio mientras regresan) y en el resto predominan las opiniones de darles documentos de residencia y empleo como son Baja California Norte y Coahuila, territorios de tránsito hacia California y Texas respectivamente. La postura de regresarlos a su país no es predominante en ningún estado, sin embargo solamente en tres alcanzó porcentajes altos de 17\% (Baja California Sur, Campeche y Oaxaca), solamente en tres se registraron porcentajes mínimos (Baja California Norte, Colima y Morelos). La postura de cerrar la frontera fue la respuesta minoritaria, pero en nueve se ubicó por encima del uno por ciento, de los cuales el Estado de México fue el más alto con 2.5. 
En cuanto a los resultados del cálculo de análisis de correspondencias múltiples, la prueba señala que el valor de la varianza explicada del modelo es de .519 y el Alfa de Cronbach de .593; de modo que más de la mitad de las inercias son explicadas.

La variable con mayor influencia en la conformación del diagrama es la edad con valores de .628 en dimensión uno y .545 en la dos. En seguida la situación laboral con .501 y .530, Estado civil .501 y .530, nivel de instrucción .504 y .197. Las contribución de la clase social es de .054 para el primer eje, .053 para el segundo; sexo influye más en el eje primero 0.63 y es casi nula en el y con .000 . Por último la religión aporta en .028 y .004.

La dispersión de las categorías de la variable dependiente conforman el referente observacional en los cuadrantes del diagrama, exponiendo las relaciones con las categorías de las independientes definiendo tres conjuntos (Figura 1). 


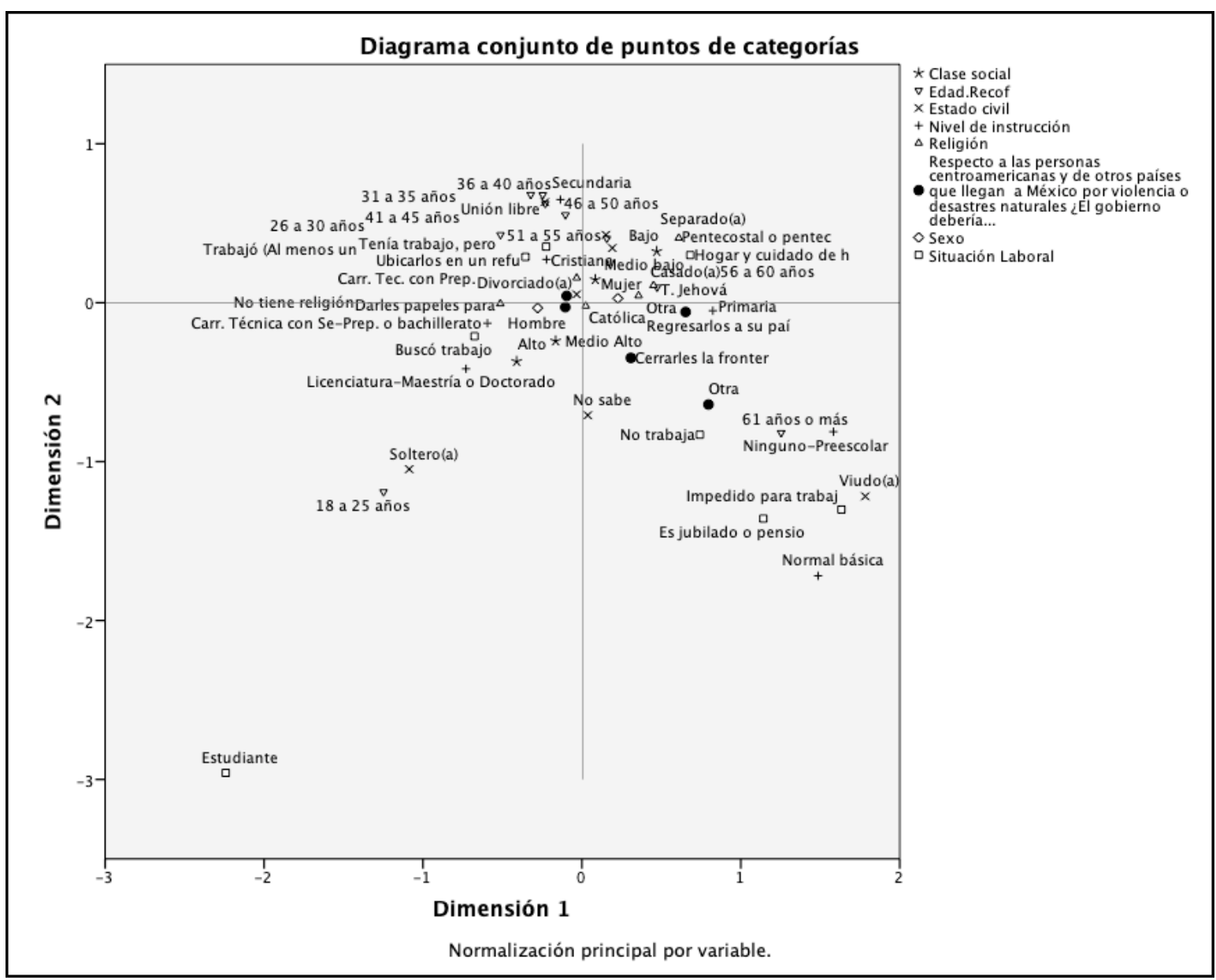

Figura 1. Distribución de posturas sobre movilidad humana por México.

Fuente: Elaboración propia con base en Encuesta Nacional de Discriminación 2017.

El primero cuya referencia es la categoría "Ubicarlos en un refugio hasta que puedan regresar" se asocia con categorías de empleo activo como son "Trabajó (Al menos una hora)" y "Tenía trabajo pero no trabajó"; con la religión cristiana, de estudios básica secundaria y media superior técnica con bachillerato; edades entre 26 a 50 años y de estado civil sin núcleo familiar: unión libre y divorciado(a).

El segundo, cuya referencia es la categoría: "Darles papeles para que vivan y trabajen aquí" se localiza en el mismo cuadrante que categorías de escolaridad de media superior como carreras técnica, preparatoria o bachillerato y superiores como licenciatura, maestría y doctorado; con clase social media alta y alta, de sexo varón y de condición laboral de búsqueda de empleo. 


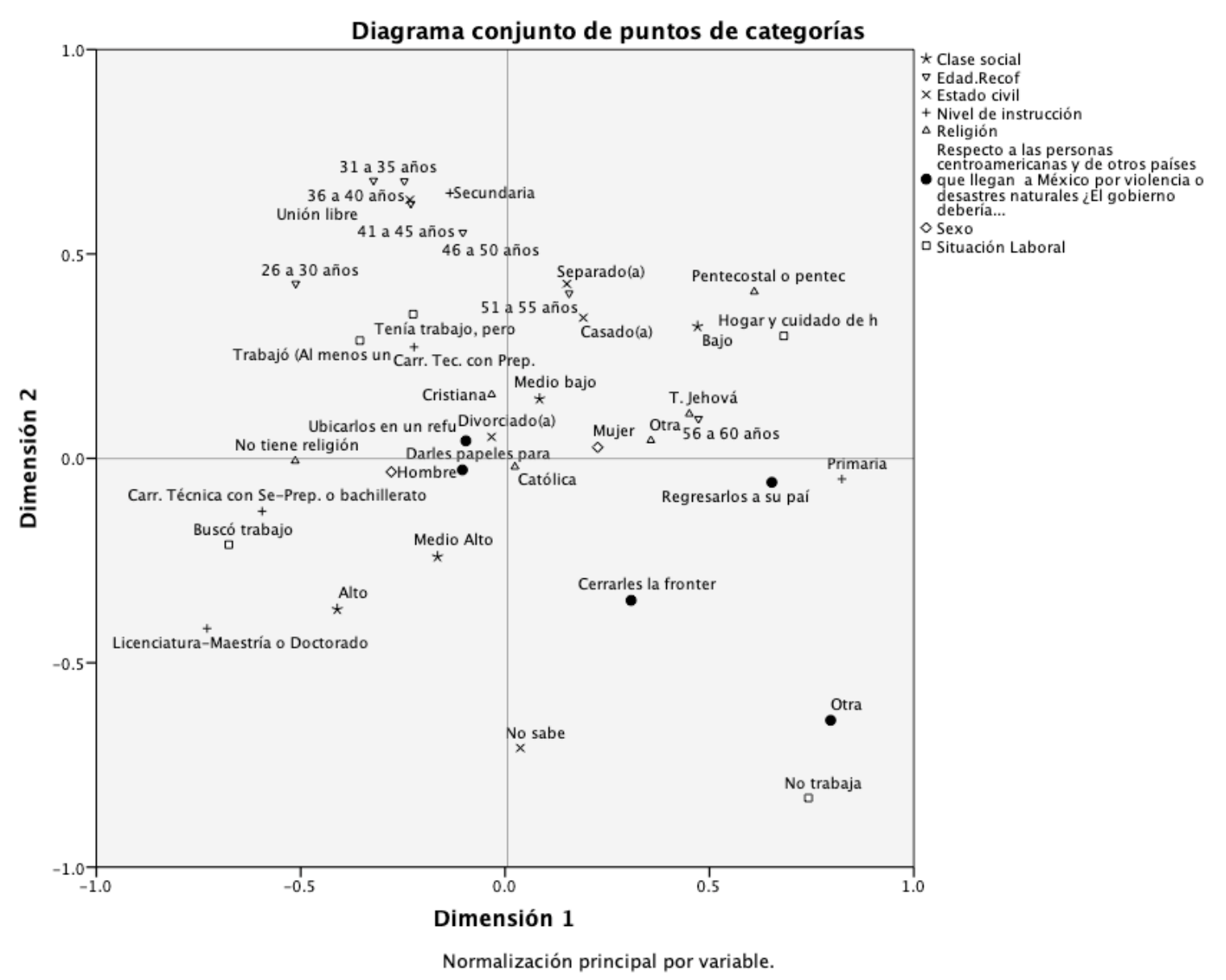

Figura 1.1. Distribución de posturas sobre movilidad humana por México (Acercamiento). Fuente: Elaboración propia con base en Encuesta Nacional de Discriminación 2017.

El último grupo de categorías conglomera a aquellas de la variable dependiente "Regresarlos a su país" y "Cerrarles la frontera" que se vinculan con el tipo de religión católica, de educación nula, preescolar y básica, sin empleo, impedido para trabajar y jubilado o pensionado; estado civil viudez y en el rango de edad de adulto mayor.

Se observa que, a pesar de que las categorías de la variable dependiente son cuatro, únicamente se construyen tres agrupaciones definidas, reduciéndose así las posturas entre una francamente excluyente, otra de apoyo moderado y la última de inclusión.

Discusión 
Las posturas frente a la movilidad humana en México son abiertamente ambivalentes entre la inclusión y exclusión, rasgo que es propiamente definitorio de las sociedades contemporáneas (Bauman, 2005), sin embargo la distribución porcentual de informantes que su ubican del lado del espectro del apoyo temporal es más de la mitad de la muestra estadística (53.3\%) y una tercera parte se ubica en la postura de inclusión (33.3\%). Minoritariamente, aunque con un peso significativo mediáticamente, son aquellos (as) con posiciones de rechazo al arribo mediante el cierre de fronteras (1\%) o la extradición (12\%).

Es fundamental señalar que para este caso las posiciones de informantes en mayoría se inclina hacia el apoyo temporal o definitivo. Una posible explicación se debe a que la temática de la movilidad humana es una constante en los imaginarios colectivos; desde el mito fundacional de la civilización hegemónica Mexica cuyo relato alude poblaciones peregrinas en búsqueda del asentamiento predicho y después la relación con otra movilidad humana llegada de Europa que se asentó y "mezcló" con la nativa, formando así un pilar del mito nacionalista durante más de un siglo (Navarrete, 2016). Además, el tema ha estado presente en la historia del país ya que es calificado como uno de los principales países expulsores de personas hacia Estados Unidos (Zepeda y Rosen, 2016) y como se ha referido, ahora es un país de tránsito. De estas circunstancias se conjetura que la experiencia social de contacto permanente con el proceso de movilidad y la cotidianidad con personas centroamericanas o caribeñas en tránsito provocan un grado de empatía fenomenológica por parte de locales ya que la proximidad con personas ajenas al círculo social en situación vulnerable pero que experimentan circunstancias vividas en primera o tercera persona (con familiares) despiertan sentimientos de solidaridad dentro de los marcos de posibilidad individual o colectiva (Muñoz, 2017).

También de forma abierta se ha señalado de las contribuciones que los(as) agentes en tránsito hacen en las poblaciones de arribo y tránsito que coadyuva a mejorar su imagen pública. Un ejemplo son las brigadas de hondureños, guatemaltecos, salvadoreños y nicaragüenses que realizaron labores de limpieza, rescate y reconstrucción de zonas afectadas al sur del país tras el terremoto que azotó México en septiembre de 2017 (Manzo, 10 septiembre 2017). También se ha documentado que, por décadas, la calidad de la producción del café en Chiapas depende de la mano 
de obra guatemalteca, sobre todo en el proceso de vivero y selección del producto, favoreciendo sustantivamente en el desarrollo local (ONU Mujeres-IMUMI, 2015). Aunado a la construcción de regiones solidarias, multiculturales, interculturales, redes de apoyo a otros transmigrantes a partir de saberes "desde abajo" que agilizan y disminuyen riesgos durante el trayecto (Flores, 2010). De forma que las ventajas son varias e importantes al grado que, por ejemplo, en Estados Unidos aportan el cuatro porciento del PIB (Delgado, 2016).

Así las tesis que señalan a sociedades en desarrollo de condiciones laborales adversas vinculadas a sentimientos de rechazo u hostilidad hacia agentes en movilidad resultan en cierto grado debatibles con estos resultados, ya que si se considera que el territorio de recepción o tránsito es de altos índices de expulsión de población así como de semejantes condiciones materiales o de seguridad pública, para este caso el esquema no aplica suficientemente. Sin embargo, es menester profundizar en indagaciones empíricas ulteriores para aseverarlo puntualmente.

En cuanto la distribución porcentual según entidad federativa, los resultados de la comparación ubican al estado de Baja California (cuya ciudad fronteriza más importante es Tijuana y principal cruce hacia E.U.A.) como el que mayor porcentaje señala opiniones incluyentes porque el 56.4\% refirió optar por otorgamiento de permisos para vivir y trabajar en el país, ninguna respuesta consideró el cierre de la frontera, el 38.8\% aludió al apoyo temporal en refugios y solo el $4.1 \%$ a la postura de "regresarlos a su país". Las razones de esta tendencias de apertura obedece a que la entidad ha tenido habitual contacto con la diversidad de procedencias y culturas. Se documenta que ancestralmente era espacio de confluencias entre lenguas como paipai, tipai, cucapá de diez comunidades de la zona serrana y del valle. En el siglo XVIII arribó población europea que abrió las puertas a colonizadores y misioneros dominicos. En el XIX llegaron alemanes, franceses y norteamericanos. En el XX hindúes, chinos, japoneses y rusos; contemporáneamente personas de Centroamérica además del centro-sur de México. Ello definió a la zona como un espacio de diversidad, apertura así como solidaridad; sin exenciones discriminatorias por razones de procedencia (Garduño, 2016), que sin embargo son rasgos minoritarios pero mediáticamente visibles. Incluso es la entidad con más cantidad de refugios oficialmente registrados del país ante instancias internacionales sumando veinticuatro (Organización Internacional para las Migraciones/OIM México, 2018). En escenario similar de apoyo se ubica Coahuila, estado 
fronterizo de paso por la ciudad Piedras Negras; ya que el $48.9 \%$ de encuestados(as) apuntó hacia la empatía e integración, el $0.5 \%$ refirió el cierre de frontera, $38.6 \%$ al refugio provisional de apoyo y solamente el $11.6 \%$ se inclina hacia devolverlos a su país. En esta entidad se documentan cinco refugios (Organización Internacional para las Migraciones/OIM México, 2018).

El resto de estados fronterizos del norte (Sonora, Chihuahua, Nuevo León y Tamaulipas) mantienen un porcentaje parecido $(34.5 \%, 35.3 \%, 36.6 \%$ y $37.8 \%$ respectivamente $)$ de encuestados que refirieron la opción de integración. Al mismo tiempo son cercanos en proporción a la postura de refugio temporal (fluctuando en el 50\%), de negación o cierre de frontera (sin sobre pasar el $1 \%$ ) y en retornarlos(as) a sus países $(12.6 \%, 13.5 \%, 12.5 \%)$ superando el promedio nacional de 12\%; exceptuando Tamaulipas con valores menores a 9\%. Las posibles razones de las diferencias hacia la tendencia de exclusión en Tamaulipas puede explicarse por la competencia económica entre locales y extranjeros de paso en el empleo de pizca de cítricos, cuyos dueños prefieren a externos(as) por que implican salarios precarios, sin compromisos de seguridad o estabilidad (Andrade-Rubio, 2016). Esto ocasiona prejuicios negativos entre la población inmersa en contextos de violencia, pobreza o ambas (Izcara-Palacios, 2012). Para el caso de Sonora se documenta el rasgo discriminatorio violento en sus antecedentes contra entonces inmigración china, cuyo tono no tenía comparación y fue lugar del origen de la campaña nacional (De la Rosa, 2016) que concluyó en genocidio. Contemporáneamente se documentan actitudes excluyentes contra migrantes indígenas en estudiantes universitarios urbanos (Laborín, Parra, y Valdéz, 2012); paradójicamente la entidad cuenta con 12 refugios de migrantes (Organización Internacional para las Migraciones/OIM México, 2018) y una legislación que reconoce derechos mínimos de los y las migrantes desde 2007 (Vilches, 2011).

Con Chihuahua, desde diversos momentos se ha diagnosticado como una entidad con alto grado de exclusión contra personas en movilidad desde las instituciones mediante su criminalización (Casillas, 1996). Incluso recientemente llamó la atención por persecuciones policiacas con motivos discriminatorios (Redacción/Proceso, 5 diciembre 2017). En Nuevo León la situación no es tan distinta ya que se ha documentado ser el estado con mayor número de denuncias contra policías por abusos contra migrantes (Silva, 2014) y altos niveles de discriminación contra migrantes por razones de "raza” (Vázquez, 2014). 
En la frontera sur, compuesta por las entidades de Quintana Roo, Tabasco, Campeche y Chiapas, las consideraciones se orientan en diversos sentidos. Por un lado Tabasco se inclina a considerar por debajo, del estándar nacional, soporte temporal y por arriba en regresarlos a su país. Una posible explicación de ello se debe a que esa frontera (El Peten) es un punto de arranque de la migración centroamericana con afluencia constante y se caracteriza por el tráfico ilegal de diversos objetos como madera, chicle, piezas arqueológicas, fauna, ganado, y más (Arriola, 2009); entre ese mercado subterráneo son significados negativamente a migrantes centroamericanos. Lo que conlleva actitudes discriminatorias por parte de la sociedad civil en general y vejaciones a los derechos humanos de manera recurrente (Bolio, Bolio y Vences, 2019).

En el caso de Quintana Roo, ruta de paso de centroamericanos(as) y caribeños(as), su tendencia porcentual se ubica inferior al promedio en apoyo temporal, pero por arriba en la integración y con mayor proporción hacia el cierre de frontera. Esto es congruente con su situación ya que es una de las entidades con más extranjeros(as) residentes legales con trabajo formal (Barrachina, Ramos y Monjaraz, 2013); pero a nivel percepciones sociales se han documentado actitudes excluyentes contra personas en movilidad interna en zonas urbanas, particularmente contra indígenas (Horbath, 2018).

Por otro lado, Campeche manifiesta otra tendencia porque su porcentaje de informantes que opinan que el gobierno debiera regresarlos a su país y cerrar las fronteras es superior a la media nacional. Además el porcentaje que apunta al apoyo provisional es inferior a la media pero no así la que manifestó otorgamiento de documentos para vivir y trabajar legalmente. Esta entidad ha participado como espacio de refugio legal en los albores de la masiva movilidad humana en la década de los ochenta (Ruiz, 2018) sin embargo se ha señalado que la cultura imperante es de exclusión por razones de condición o clase social y racismo (González, 2015). Además es uno de los miembros de la federación que prohíbe a ciudadanos(as) naturalizados(as) acceder a cargos públicos (Alonso, 2018).

En Chiapas, cuya historia fundacional implica la división de los pueblos y familias por el trazo de fronteras entre México y Guatemala en el siglo XIX (Ruiz, 2018), por lo que las divisiones 
entre personas nacionales y extranjeras fue prácticamente inexistente (Castillo y Toussaint, 2015). Uno de los rasgos definitorios de esta entidad es la predominancia de comunidades indígenas en marginalidad, pobreza y el desentendimiento por parte del gobierno central durante décadas; así como la sistemática discriminación de los beneficios del estado moderno hasta la Primera Declaración de la Selva Lacandona del movimiento armado Ejército Zapatista de Liberación Nacional (EZLN) en 1994 (Ramírez, 2003).En cuanto a inmigrantes y refugiados(as) se generaron procesos de exclusión en la década de los ochenta, ya que diversos grupos se asentaron en rancherías y campamentos bajo condiciones vulnerables. Pero también se instalaron en comunidades indígenas, conformándose como minorías étnicas a las que se les exigió cuotas económicas, trabajos colectivos, religiosos; además de vivir estigmatizados (Ruiz, 2018); aunado a las constantes vejaciones de derechos humanos que padecieron durante su tránsito, exacerbándose contra mujeres (Centro de Derechos Humanos Miguel Agustín Pro Juárez, A.C., 2017).

Además, hay coincidencias en la mayoría de entidades fronterizas donde predominan informantes de postura de no inclusión con las señaladas de alto riesgo durante los traslados (Comisión Nacional de Derechos Humanos, 2018, pp. 119) como Sonora, Chihuahua, Nuevo León, Tamaulipas, Tabasco y Chiapas. El resto, Baja California y Coahuila, son denotadas en este grupo a pesar de que en el análisis predomina la tendencia a la integración o apoyo temporal. Para el caso de la frontera sur, los estados de Quintana Roo y Campeche de tendencias relativamente elevadas hacia el cierre de fronteras son comprendidos de bajo riesgo.

Con respecto a la relación de posturas con categorías de variables de control el resultado de su iteración conformó tres grupos definidos distribuidos en abierta inclusión, apoyo temporal y rechazo categórico.

Las categorías de situación laboral activa mantienen una relación positiva con actitudes de apoyo temporal a personas en movilidad mientras que aquellas de desempleo, impedido para trabajar o en jubilación mantienen proximidad con el rechazo puntual. Estas respuestas coinciden con los marcos básicos de explicación economicista o instrumental de las actitudes ante la movilidad ya que se señalan que las personas en estatus de trabajadores no temerán el arribo de 
externos para competir por su puesto laboral, a diferencia de las(os) que se encuentran en circunstancias de precariedad o desempleo (Polanyi, 2007; Markaki y Longhi, 2013); a pesar de que estos informantes tuvieron claro que la movilidad no se realiza en su espacio vital inmediato sino que solamente se trasladan hacia otro país.

La categoría laboral "en búsqueda de empleo", se vincula con la opinión de incluir definitivamente a las personas en movilidad. Las posibles razones de ello se deben a que las condiciones laborales adversas del país (ya que casi el 60\% de los empleos son informales aunado a una tasa de desempleo de poco más de $4 \%$ y la actividad restante se caracteriza por la precariedad) hacen comprender empáticamente la situación específica de búsqueda de bienestar mínimo por cualquier medio. Tal y como ha sucedido en la zona metropolitana de Guadalajara, caracterizada por la marginación y precariedad, donde informantes muestran genuina empatía (sic) hacia migrantes por estar en igualdad de condiciones (Dignidad y justicia en el camino A.C., 2016).

La religión como variable influyente en las opiniones se distribuye en relación entre cristianismo con posturas de apoyo temporal, mientras que el catolicismo lo hace con el rechazo. Esto es coincidente con estudios que históricamente describen a grupos e iglesias cristianasprotestantes como pioneras en ejercicios de acogida de migrantes centroamericanos en México (García, Basail y Villafuerte, 2008) en un contexto de reprobación a la movilidad de agentes con credos no católicos (Alanís, 1996). Contemporáneamente existen colectivos católicos de influencia considerable en esferas públicas para proteger derechos humanos además de realizar pronunciamientos de abierto apoyo así como la extendida edificación de refugios; sin embargo habría que explorar a detalle la tendencia paradójica que se encuentra en este estudio con respecto a informantes católicos no afiliados a agrupaciones de apoyo para rastrear alguna tendencia y explicación.

La distinción de posturas en función del sexo de informantes se orienta hacia varones como más próximos a integración de personas en movilidad, lo que contrasta con evidencias cualitativas de percepción de los propios sujetos en movilidad quienes apuntan a éstos como sujetos con pronunciaciones hostiles, violentas y discriminatorias a diferencia de mujeres (Aranda, 2016). También coincide con resultados empíricos en contextos estadounidenses donde los varones 
muestran actitudes de mayor apertura en comparación a mujeres; las razones obedecen a tendencias conservadoras de ellas por cuestiones de seguridad familiar (Donato y Pérez, 2016). Hipotéticamente se explica esta directriz ya que la ligera mayoría de población migrante internacional (Terrón-Caro y Monreal-Gimeno, 2014) y mexicana se compone de varones (Wegrzynowska, 2015) que, como señalamos antes, expresan una clara empatía hacia las personas centroamericanas; por lo tanto la idea de trasladarse por razones materiales está presente en los marcos de orientación de valor y acción de los sujetos típicamente proveedores de núcleos familiares.

En cuanto a la edad, el estrato más joven se relaciona con la postura de inclusión: de 26 a 50 años con apoyo temporal y los adultos mayores con rechazo. De forma que la tendencia se orienta hacia una correlación de entre más edad menos apoyo. La interpretación de este resultado tiene como supuesto que edades avanzadas poseen un referente de arraigo hacia los esquemas nacionalistas y respeto irrestricto de las leyes, mientras que jóvenes se orientan por otras lógicas o normas tácitas al cambio generacional, tal como se explica en otros contextos ( $\mathrm{O}^{\prime}$ Rourke y Sinnott, 2006). Es importante señalar que una posible explicación responde a que el sector joven se localiza en el mismo cuadrante del diagrama que la actividad de estudiante, de forma que se infiere aún no participan activamente en el mercado de trabajo, así no los consideran de riesgo para la competencia: mientras quienes laboran y se encuentran en edades productivas opinan apoyo temporal por consideraciones empáticas ya referidas.

Con la misma tendencia el nivel educativo, porque entre más años escolares la opinión se torna de integración mientras que entre menos escolaridad es más próxima al rechazo. De forma coincidente la educación intermedia se relaciona con orientaciones de apoyo temporal. Tal propensión es compatible con distintos estudios empíricos previos en otros contextos (ZamoraKapoor, Kovincic y Causey, 2013), que aportan razones donde el cosmopolitismo adquirido en la academia permiten considerar como positiva la incorporación de nuevos miembros por las ventajas económicas y culturales que incentivan (Willems, 1995). Por otro lado, una razón económica es que las personas más instruidas poseen calificaciones y competencias para contender en el mercado laboral, mermando temores de perder su fuente de ingresos (Meseguer y Maldonado, 2015). También la clase social puede ser explicada según esta directriz por razones semejantes, ya que es 
en los estratos con mejor condición económica donde se ubican las opiniones de incorporación completa; congruente con estudios empíricos en contextos europeos (Kunovich, 2004).

Por último, el estado civil sin conformación de núcleo familiar, particularmente unión libre y divorcio, resultan influyentes para estimar apoyo temporal; mientras la viudez se asocia con exclusión tajante. Esta última ilación resulta discordante con ejercicios empíricos precedentes ya que se vincula con casados (Gordon, 2015; Brenner, y Fertig, 2006) quienes fundamentan preocupación por estabilidad así como seguridad material de la familia en algunas sociedades europeas (Ceubanu y Escandell, 2010). Por otra parte, las posibles explicaciones de esta orientación en informantes enviudados(as) se deba a la coincidencia con edades adultas mayores, las cuales han sido asociadas con posturas conservadoras política y culturalmente tradicionalistas. Sin embargo habría que profundizar en lo sucesivo esta conexión en busca de evidencia que lo testifique.

\section{Conclusiones}

Las posturas de informantes mexicanos(as) con respecto a la movilidad humana contemporánea de tránsito es mayoritariamente de apoyo temporal (53.3\%), una tercera parte señaló aceptación para integrarse al país legalmente (33.3\%), poco más de una décima parte (12\%) opinó devolverlos a sus países de origen y de forma categórica la minoría (1\%) se posicionó por el cierre de fronteras.

La distribución de estas opiniones en estados fronterizos del sur coinciden en priorizar apoyo temporal o refugio, pero muestra también opiniones de rechazo proporcionalmente superiores a la media nacional, excepto Quintana Roo. Mientras que al norte únicamente en Coahuila y Baja California, ponderan la aceptación definitiva y la postura de deportación se ubica por debajo del promedio; en el resto predomina la preferencia por el refugio temporal.

La relación de categorías de variables de control con las pertenecientes a la variable dependiente mediante análisis multifactorial, construyeron tres agrupaciones: El primero con postura de apoyo temporal o refugio es una agente hipotético en empleo activo porque "Trabajó 
(Al menos una hora)" y "Tenía trabajo pero no trabajó"; de religión cristiana, con estudios básicos de secundaria y media superior técnica con bachillerato; en edades entre 26 a 50 años y de estado civil sin núcleo familiar: unión libre o divorciado(a).

El otro conjunto que opinó "darles papeles para que vivan y trabajen aquí" se ubica en informantes de escolaridad de media superior, carreras técnica, preparatoria/bachillerato y superior como licenciatura, maestría y doctorado; de clase social media alta y alta, particularmente varón y en búsqueda de empleo. Por último el tercer perfil de contundente rechazo con posturas de "Regresarlos a su país" y "Cerrarles la frontera" se vinculan con el tipo de religión católica, de educación nula, preescolar y básica; sin empleo, impedido para trabajar y jubilado o pensionado; estado civil viudez y en el rango de edad de adulto mayor.

Con estos resultados se pretende abonar al estado de conocimiento acerca de un rasgo de la tradición científica de la movilidad humana, pero aplicado al caso de México contemporáneo, el cual ha tenido características inéditas desde hace unos pocos años. De manera que profundizar sobre las opiniones de poblaciones con necesidades elementales visibles frente a otras, motivadas a desplazarse por semejantes circunstancias de carencia, ofrecen posibilidades y retos de comprensión e interpretación epistemológicamente diversas que rebasan la simple descripción del cambio de residencia típicamente conceptualizado como migración.

\section{Referencias}

Alanís, F. (1996). Los extranjeros en México, la inmigración y el gobierno: ¿tolerancia o intolerancia religiosa?. Historia Mexicana, 45(3), 539-566. Recuperado de https://historiamexicana.colmex.mx/index.php/RHM/article/viewFile/2316/2883

Alonso, G. (2019). La antropología de las migraciones clandestinas en tiempos de neo-movilidades alternativas y el muro de Donald Trump. Religación. Revista de Ciencias Sociales y Humanidades, 4(4), 16 - 31. Recuperado de http://revista.religacion.com/article-alonsoguillermo.html 
Alonso, I. (2018). Discriminación hacia mexicanos naturalizados para acceder a cargos públicos en México. Revista Legislativa de Estudios Sociales y de Opinión Pública, 11(22), 111 142. Recuperado de https://dialnet.unirioja.es/servlet/articulo?codigo=6579535

Andrade-Rubio, K. (2016). Víctimas de trata: mujeres migrantes, trabajo agrario y acoso sexual en Tamaulipas. Ciencia UAT, 11(1), 22-36. Recuperado de http://www.redalyc.org/articulo.oa?id=441946945002

Aranda, A. (2016). Estigma y discriminación: Narrativas de migrantes centroamericanos en tránsito por México hacia Estados Unidos. (Tesis de maestría en estudios culturales). Tijuana: El Colegio de la Frontera Norte. Recuperado de https://www.colef.mx/posgrado/wp-content/uploads/2016/12/TESIS-Aranda-ReynosoAd\%C3\%A1n-Emir.pdf

Arriola, L. (2009). Seguridad y migración en el espacio fronterizo Tabasco-El Peten. Migración y desarrollo, 13, 77-95. Recuperado de http://www.scielo.org.mx/pdf/myd/n13/n13a2.pdf

Asamblea General de la ONU (2016). Declaración de Nueva York para los refugiados y Migrantes. New York: ONU. Recuperado de https://undocs.org/es/A/71/L.1

Barfield, T. (2000). Diccionario de antropología. México: Siglo XXI editores.

Barrachina, C., Ramos, J. y Monjaraz, A. (2013). Quintana Roo en el contexto migratorio mexicano. En E. Baltar, M. Marroni y D. Villafuerte (Coords.). Viejas y nuevas migraciones forzadas en el sur de México, Centroamérica y el Caribe (pp. 271-314). México: Universidad de Quintana Roo. Recuperado de https://www.researchgate.net/profile/Jimmy_Ramos/publication/319122180_Quintana_R oo_en_el_contexto_migratorio/links/59a2ff91aca2726b90285759/Quintana-Roo-en-elcontexto-migratorio.pdf

Batista, J. y Sureda, J. (1987). Análisis de correspondencias y técnicas de clasificación: su interés para la investigación en las ciencias sociales y del comportamiento. Journal of the study of education and development, 10(39-40), 171-186. Recuperado de $\underline{\text { https://dialnet.unirioja.es/servlet/articulo?codigo }=749270}$

Bauman, Z. (2005). Modernidad y ambivalencia. Barcelona: Anthropos.

Bauman, Z. (2016). Extraños llamando a la puerta. Barcelona: Paídos. 
Beck, U. (2007). Cómo los vecinos se convierten en judíos. La construcción política del extraño en una era de modernidad reflexiva. Papers. Revista de Sociología, 84, 47-66. Recuperado de http://dx.doi.org/10.5565/rev/papers/v84n0.1632

Bolio, H., Bolio, J. y Vences, R. (2019). Trabajo social y Derechos Humanos. El papel de la burocracia en la frontera Petén-Tabasco. Revista Salud y Bienestar Social, 3(1), 39-54. Recuperado de http://www.revista.enfermeria.uady.mx/ojs/index.php/Salud/article/view/66

Brenner, J. y Fertig, M. (2006). Identifying the determinants of attitudes towards immigrants: A structural cross-country analysis. RWI Discussion Paper No. 47. Recuperado de http://ftp.iza.org/dp2306.pdf

Brenner, J., \& Fertig, M. (2006). Identifying the determinants of attitude towards immigrants: A structural cross.country analysis. Germany: IZA, (Discussion Paper, 2306). Recuperado de http://ftp.iza.org/dp2306.pdf

Canales, A. y Rojas, M. (2018). Panorama de la migración internacional en México y Centroamerica. Documento elaborado en el marco de la Reunión Regional Latinoamericana y Caribeña de Expertas y Expertos en Migración Internacional preparatoria del Pacto Mundial para una Migración Segura. Santiago: CEPAL-ONUOIM. Recuperado de https://repositorio.cepal.org/bitstream/handle/11362/43697/1/S1800554_es.pdf

Castillo, M. y Toussaint, M. (2015). La frontera sur de México: orígenes y desarrollo de la migración centroamericana. Cuadernos de Inter-c-a-mbio sobre Centroameríca y el Caribe, 12(2), 59-86. Recuperado de https://revistas.ucr.ac.cr/index.php/intercambio/article/view/21700

Centro de Derechos Humanos Miguel Agustín Pro Juárez, A.C. (2017). Criminalización de mujeres migrantes. Análisis de seis casos en la frontera sur. México: Centro PRODH/Universidad Iberoamericana Ciudad de México/Programa de Asuntos Migratorios/Centro de Derechos Humanos Fray Matías de Córdova, A.C.

Centro de Estudios Internacionales Gilberto Bosques (2015). México en la encrucijada: Implicaciones internas e internacionales de la migración. México: Senado de la República LVIII Legislatura. Recuperado de http://www.senado.gob.mx/BMO/index_htm_files/Mexico_encrucijada_distribucion.pdf 
CEPAL (10 de diciembre de 2018). Cancilleres de El Salvador, Guatemala, Honduras y México presentaron Plan de Desarrollo Integral en el marco de la Conferencia para el Pacto Mundial sobre migración [Comunicado de prensa ]. Recuperado de https://www.cepal.org/es/comunicados/cancilleres-salvador-guatemala-honduras-mexicopresentaron-plan-desarrollo-integral

Ceubanu, A. y Escandell, X. (2010). Comparative analyses of public attitudes toward immigrants and immigrations using multinational survey data: A review of theories and research. Annual Review of Sociology, 36, 309-328. Recuperado de http://doi.org/10.1146/annurev.soc.012809.102651

Colino, C. (2009). Método comparativo. En Diccionario crítico de ciencias sociales. Terminología científico-social. Madrid: Plaza y Valdes/Universidad Complutense de Madrid. Obtenido de http://webs.ucm.es/info/eurotheo/diccionario/M/metodcomparativo_b.htm

Comisión Nacional de los Derechos Humanos. (2018). Los desafíos de la migración y los albergues como oasis. Encuesta nacional de personas migrantes en tránsito por México. Ciudad de México: Comisión Nacional de los Derechos Humanos/Instituto de Investigaciones Jurídicas-Universidad Nacional Autónoma de México. Recuperado de https://www.cndh.org.mx/sites/all/doc/Informes/Especiales/Informe-Especial-Desafiosmigracion.pdf

Consejo Nacional de Población, Fundación BBVA Bancomer y BBVA Research. (2017). Anuario de migración y remesas: México 2017. México: CONAPO y Fundación BBVA Bancomer. Recuperado de https://www.bbva.com/wpcontent/uploads/2017/07/1707_AnuarioMigracionRemesas_2017.pdf

Consejo Nacional para Prevenir la Discriminación e Instituto Nacional de Estadística y Geografía. (2017). ENADIS. Encuesta Nacional sobre Discriminación 2017. Principales resultados. México: INEGI. Recuperado de https://www.conapred.org.mx/userfiles/files/PtcionENADIS2017_08.pdf

Crowder, K. y Hall, M. (2007). Migration: internal. En G. Ritzer (Ed.). The Blackwell Enciclopedia of Sociology (pp. 3014-3019). Maiden, Ma.: Blackwell Pub. Recuperado de DOI: $10.1002 / 9781405165518$

De la Rosa, E. (2016). Discriminación de los inmigrantes chinos en Sonora. Un estudio sobre ideas, políticas públicas y leyes migratorias en el contexto transfronterizo y estatal (1920-1934). 
(Tesis de maestría en historia internacional). México: Centro de Investigación y Docencia Económica A.C. CIDE. Recuperado de http://repositoriodigital.cide.edu/bitstream/handle/11651/743/000153069.pdf?sequence=1

Deldago, R. (2016). Reflexiones sobre la cuestión migratoria México-Estados Unidos ante el triunfo electoral de Donald Trump. Migración y Desarrollo, 14(27), 167-178. Recuperado de http://www.redalyc.org/pdf/660/66049818006.pdf

Dignidad y justicia en el camino A.C. (2016). El desafío de transitar-vivir en la ciudad para las personas migrantes en Guadalajara. Guadalajara: FM4 Paso libre. Recuperado de https://fm4pasolibre.org/wp-content/uploads/2018/07/INFORM1.pdf

Donato, K. y Pérez, S. (2016). A different hue of the gender gap: Latino immigrants and political conservatism in the Unted States. RSF: The Russel sage foundation journal of the social sciences, 2(3), 98-124. Recuperado de http://www.jstor.org/stable/10.7758/rsf.2016.2.3

Dudley, P. (2006). Migration. En B. Turner (Ed.). The Cambridge dictionary of sociology (pp. 384386). New York: Cambridge University Press.

Flores, M. (2010). El impacto positivo de la migración centroamericana en tránsito: vida cotidiana en localidades de Veracruz, Tabasco y Estado de México. (Tesis apara obtener el título de licenciada en historia). México: Universidad Nacional Autónoma de México. Recuperado de

https://www.academia.edu/17749623/El_impacto_positivo_de_la_migraci\%C3\%B3n_cen troamericana_en_tr\%C3\%A1nsito_por_M\%C3\%A9xico._Vida_Cotidiana... tesis_para_o btener_el_grado_de_Licenciada_en_Historia_

Fuentes, C. y Márquez, M. (2006). Actitudes ante la inmigración. El reflejo lingüístico. Sevilla: Junta de Andalucía, España.

Galimberti, U. (2002). Diccionario de psicología. México: Siglo XXI editores.

Gall, O. (2018). Racismo y xenofobias mexicanos frente a los migrantes: 1910-2018. REMHU, Revista Interdisciplinaria da Mobilidade Humana, 26(53), 115-134. Recuperado de http://www.scielo.br/pdf/remhu/v26n53/2237-9843-remhu-26-53-115.pdf

Gallino, L. (1995). Diccionario de sociología. México: Siglo XXI editores.

García, J. (2017). Sujetos vulnerables en la trata de seres humanos. Los casos de México y España. Trayectorias Humanas Transcontinentales, 1, 1-17. Recuperado de DOI: 10.25965/trahs.74 
García, M., Basail, A. y Villafuerte, D. (2008). Migración y religión en Chiapas. Mapas migratorios y espacios religiosos a través de estudios de casos. En A. Basail y M. García (Coords.), Travesías de la fe. Migración, religión y fronteras en Brasil/México (pp. 147-200). Tuxtla Gutiérrez, Chiapas: Universidad de ciencias y Artes de Chiapas. Recuperado de http://repositorio.cesmeca.mx/bitstream/cesmeca/127/1/Traves\%C3\%ADas\%206.pdf

Garduño, E. (2016). La frontera norte de México: Campo de desplazamiento, interacción y disputa. Frontera Norte, 28(55), 131-151. Recuperado de https://fronteranorte.colef.mx/index.php/fronteranorte/article/view/194/52

Garibo, M. (2016). Migración centroamericana en tránsito por México en el marco de la externalización de la frontera estadounidense: Plan Sur y Plan Frontera Sur. PuntoCUNorte, 3, 71-102. Recuperado de http://puntocunorte.com/wp-content/uploads/2018/06/PC3-3Garibo.pdf

González-Barrera, A. y Krogstad, J. (june 28, 2019). What we know about ilegal immigration from Mexico. Factank. News in the Numbers. Pew Research Center. Recuperado de https://www.pewresearch.org/fact-tank/2019/06/28/what-we-know-about-illegalimmigration-from-mexico/

González, H. (26 mayo de 2019). "Las caravanas de migrantes representan el éxodo de la miseria”: José Manuel Valenzuela. Aristegui Noticias. Recuperado de https://aristeguinoticias.com/2605/kiosko/las-caravanas-de-migrantes-representan-elexodo-de-la-miseria-jose-manuel-valenzuela/

González, M. (2015). Líneas de acción para elaborar políticas públicas contra la discriminación en México. Razón y palabra, 19(3_91), 350-368. Recuperado de https://www.revistarazonypalabra.org/index.php/ryp/article/view/102

Gordon, S. (2015). The relationship between national well-being and xenophobia in a divided society: The case of South Africa. African Review of Economics and Finance, 7(1), 80-103. Recuperado de https://www.ajol.info/index.php/aref/article/viewFile/136026/125518

Greenacre, M. y Hastie, T. (1987). The geometric interpretation of correspondence analysis. Journal of the American Statistical Association, 82(398), 437-447. Recuperado de http://www.jstor.org/stable/2289445

Gujarati, D. y Porter, D. (2010). Econometría. México: Mc. Graw Hill. 
Hasee, R., Schneider, H. y Weigelt, K. (2002). Diccionario de economía social de Mercado. Política económica de la A a la Z. México: Fundación Konrad Adenauer A.C. Recuperado de https://www.kas.de/c/document_library/get_file?uuid=dbb63900-5475-4e59-157e$\underline{39281 \text { eef6901\&groupId }=266027}$

Horbath, J. (2018). Indígenas en tres ciudades caribeñas del sureste mexicano: percepciones de la discriminación y tensiones en su identidad. En J. Horbarth y M. Garcia (Coords.). La cuestión indígena en las ciudades de las américas. Procesos, políticas e identidades (pp. 169-187). Buenos Aires: Miño y Dávila editores/CLACSO/ECOSUR/CONACyT. Recuperado de http://biblioteca.clacso.edu.ar/clacso/se/20181206095407/La_cuestion_indigena.pdf\#page $=170$

Izcara-Palacios, S. (2012). Violencia contra inmigrantes en Tamaulipas. Europen Review of Latin America and Caribean Studies, 93, 3-24. Recuperado de http://www.jstor.org/stable/23294468

Izcara, S. (2016). Violencia postestructural: migrantes centroamericanos y cárteles de la droga en México. Revista de Estudios Sociales, 56, 12-25. Recuperado de http://www.redalyc.org/articulo.oa?id=81545040002

Kevins, A. y Lightman, N. (2019). Immigrant sentiment and labour market vulnerability: economic perceptions of immigration in dualized labour markets. Comparative European Politics, Recuperado de http://doi.org/10.1057/s41295-019-00194-1

Kritz, M. (2007). Migration: international. En G. Ritzer (Ed.), The Blackwell Enciclopedia of Sociology (pp. 3019-3025). Maiden, Ma.: Blackwell Pub. Recuperado de DOI: $10.1002 / 9781405165518$

Kunovich, R. (2004). Social structural position and prejudice: An exploration of cross-national differences in regression slopes. Social Science Research, 33(1), 20-44. Recuperado de http://doi.org/10.1016/S0049-089X(03)00037-1

Laborín, J., Parra, E. y Valdéz, G. (2012). Discriminación y prejuicios de jóvenes sonorenses hacia el migrante indígena. Estudios Sociales, 2, 333-347. Recuperado de http://www.redalyc.org/articulo.oa?id=41724972015

López, L., Fernándes, J., Sposito, E. y Trinca, D. (2015). Diccionario de geografía aplicada y profesional. Terminología de análisis y gestión del territorio. León: Universidad de León. 
Recuperado

https://www.uv.es/ javier/index_archivos/Diccionario_Geografia\%20Aplicada.pdf

Maffesoli, M. (2005). El nomadismo. Vagabundeos iniciáticos. México: Fondo de Cultura Económica.

Manzo, D. (10 septiembre 2017). Migrantes ayudan a limpiar hogares derrumbado por terremoto en el Istmo. Aristegui Noticias. Recuperado de https://aristeguinoticias.com/1009/mexico/migrantes-ayudan-a-limpiar-hogaresderrumbados-por-terremoto-en-el-istmo/

Markaki, Y. y Longhi, S. (2013). What determines attitudes to inmigration in European countries? An analysis at the regional level. Migration Studies, 1(3), 311-337. Recuperado de http://doi.org/10.1093/migration/mnt015

Márquez, H. (2015). No vale nada la vida: éxodo y criminalización de migrantes centroamericanos en México. Migración y Desarrollo, 13(25), 151-173. Recuperado de http://www.scielo.org.mx/scielo.php?script=sci_arttext\&pid=S1870-75992015000200151

MartínezHernández-Mejía, I. (2019). El paso de las caravanas de migrantes por México. Un recuento en el contexto regional. Análisis Plural, segundo semestre de 2018. Recuperado de

https://rei.iteso.mx/bitstream/handle/11117/5889/S3\%20El\%20paso\%20de\%20las\%20car avanas $\% 20$ de $\% 20$ migrantes.pdf? sequence $=2$

Mejía, C., Blancas, N. y Galindo, A. (2019). Riesgo laboral contemporáneo en informantes mexicanos(as). Estimaciones desde el Latinobarómetro 2017. Ciencias Sociales. Revista multidisciplinaria, $\quad 1(1), \quad 4-37 . \quad$ Recuperado de http://www.revista.redesfuerzoslocal.edu.mx/wp-content/uploads/2019/07/Volumen-1N\%C3\%BAmero-1.pdf

Meseguer, C. y Maldonado, G. (2015). Las actitudes hacia los inmigrantes en México. Explicaciones económicas y sociales. Foro Internacional, 55(3), 772-804. Recuperado de http://www.scielo.org.mx/scielo.php?script=sci_arttext\&pid=S0185$\underline{013 X 2015000300772}$

Mills, M., van de Bunt, G. y Bruijn, j. (2006). Comparative research - persistent problems and promising solutions. International Sociology, 21(5), 619-631. Recuperado de http://doi.org/10.1177/0268580906067833 
Montoya-Ortíz, M. y Sandoval-Forero, E. (2018). Migrantes haitianos en México: Un nuevo escenario migratorio. Huellas de la migración, 3(6), 133-156. Recuperado de https://huellasdelamigracion.uaemex.mx/article/view/11719

Muñoz, E. (2017). El concepto de empatía (Einfüblung) en Max Scheler y Edith Stein. Sus alcances religiosos y políticos. Veritas, 38, 77-95. Recuperado de https://scielo.conicyt.cl/pdf/veritas/n38/0718-9273-veritas-38-00077.pdf

Navarrete, F. (1999). Las fuentes indígenas más allá de la dicotomía entre historia y mito. Estudios de cultura nahúalt, 30, 231-256. Recuperado de http://www.historicas.unam.mx/publicaciones/revistas/nahuatl/pdf/ecn30/593.pdf

Navarrete, F. (2016). México racista. Una denuncia. México: Grijalbo.

O’Rourke, K. y Sinnot, R. (2006). The determinants of individual attitudes towards immigration. European journal of political economy, 22 (4), 838-861. Recuperado de doi: 10.1016/j.ejpoleco.2005.10.005

Odgers, O. (2005). Migración e (in)tolerancia religiosa: aportes al estudio del impacto de la migración internacional en la percepción de la diversidad religiosa. Estudios Fronterizos, $6(12)$, 39-53. Recuperado de http://www.scielo.org.mx/scielo.php?script=sci_arttext\&pid=S0187-69612005000200002 ONU Mujeres/IMUMI. (2015). Las trabajadoras migrantes centroamericanas en Chiapas. Recomendaciones de política para garantizar el ejercicio de sus derechos. México: ONU Mujeres e Instituto para las Mujeres en la Migración A.C. Recuperado de https://mexico.unwomen.org/es/digiteca/publicaciones/2014/07/las-trabajadorasmigrantes-centroamericanas-en-chiapas

Organización Internacional para las Migraciones (2018). Informe sobre las migraciones en el mundo 2018. Ginebra: Organización Internacional para las Migraciones. Recuperado de https://publications.iom.int/system/files/pdf/wmr_2018_sp.pdf

Organización Internacional para las Migraciones/OIM México. (2018). Directorio de casas y albergues para personas migrantes. México: Organización Internacional para las Migraciones. Recuperado de http://mexico.iom.int/system/files/Publicaciones/Directorio\%20de\%20Casas\%20y\%20Al bergues\%20para\%20personas\%20migrantes\%20digital_0.pdf 
París, M. (2018). Factores y condiciones del flujo migratorio y de solicitantes de asilo o refugio en Tijuana. En M. D. París (Coord.). Informe Especial. Migrantes Haitianos y centroamericanos en Tijuana, Baja California, 2016-2017. Políticas gubernamentales y acciones de la sociedad civil (pp. 20-34). México: El Colegio de la Frontera Norte y Comisión Nacional de los Derechos Humanos. Recuperado de https://www.cndh.org.mx/sites/all/doc/Informes/Especiales/Informe-Migrantes-20162017.pdf

París, M. (2018b). Vulnerabilidad social y derechos humanos de los migrantes internacionales. En M. D. París (Coord.). Informe Especial. Migrantes Haitianos y centroamericanos en Tijuana, Baja California, 2016-2017. Políticas gubernamentales y acciones de la sociedad civil (pp. 125-144). México: El Colegio de la Frontera Norte y Comisión Nacional de los Derechos Humanos. Recuperado de https://www.cndh.org.mx/sites/all/doc/Informes/Especiales/Informe-Migrantes-20162017.pdf

Passel, J. y Cohn, D. (June 12, 2019). Mexicans decline to less tan half the U.S. unauthorized immigrant population for the first time. Factank. News in the Numbers. Pew Research Center. Recuperado de https://www.pewresearch.org/fact-tank/2019/06/12/usunauthorized-immigrant-population-2017/

Polanyi, K. (2007). La gran transformación. Los orígenes políticos y económicos de nuestro tiempo. México: Fondo de Cultura Económica.

Portes, A. y DeWind, J. (2006). Un diálogo transatlántico: El progreso de la investigación y la teoría en el estudio de la migración internacional. En A. Portes y J. DeWind (Coords.) Repensando las migraciones: Nuevas perspectivas teóricas y empíricas (pp. 157-190). México: Miguel Ángel Porrúa/Universidad Autónoma de Zacatecas/Secretaría de Gobernación- Instituto Nacional de Migración.

Quillian, L. (1995). Prejudice as a reponse to perceived group threat: population composition and anti-immigrant and racial prejudice in Europe. American Sociological Review, 60(4), 586611. Recuperado de http://www.jstor.org/stable/2096296

Rama, C. (1976). Migraciones en América Latina. En Términos Latinoamericanos para el Diccionario de Ciencias Sociales (pp. 103-107). Buenos Aires: Consejo Latinoamericano 
de Ciencias $\quad$ Sociales. $\quad$ Recuperado de http://biblioteca.clacso.edu.ar/ar/libros/historico/rama.pdf

Ramírez, J. (2003). ¡Nunca más sin rostros! (Evolución histórica del proyecto del EZLN). México: Ediciones EON/El Cotidiano.

Rebolledo, O. (2017). México: Identidad, diversidad y extranjería. Revista de Ciencias Sociales (Cr), IV(158), 45-59. Recuperado de http://www.redalyc.org/pdf/153/15354921004.pdf

Redacción AN. (24 octubre de 2018). 52\% de mexicanos, a favor del libre paso de la caravana migrante: encuesta. Aristegui noticias. Recuperado de https://aristeguinoticias.com/2410/mexico/52-de-mexicanos-a-favor-del-libre-paso-de-lacaravana-migrante-encuesta/

Redacción/Proceso. (5 diciembre 2017). Criminalización y cacería de migrantes en Chihuahua. Proceso. Recuperado de https://www.proceso.com.mx/513874/criminalizacion-y-caceriade-migrantes-en-chihuahua

Ruiz, V. (2018). Los refugiados guatemaltecos y la frontera-frente de discriminación, explotación y desigualdad. Alteridades, 28(56), 47-57. Recuperado de http://www.scielo.org.mx/pdf/alte/v28n56/2448-850X-alte-28-56-47.pdf

Sánchez, J. y Ortega, A. (2013). La iglesia católica y los migrantes mexicanos en el mosaico religioso de los Estados Unidos. Los casos de California y Utah. Tla-melaua, 7(35), 130148. Recuperado de http://dx.doi.org/10.32399/rtla.7.35.57

Sandoval, C. (2015). No más muros. Exclusión y migración forzada en Centroamérica. Costa Rica: Editorial Universidad de Costa Rica.

Sartori, G. (1970). Concept misformation in comparative politics. The American Political Science, 64(4), 1033-1053. Recuperado de http://www.jstor.org/stable/1958356

Schiavon, J. (2015). La migración Centroamérica-México-Estados Unidos: historias de vulnerabilidad y políticas inacabadas. Con-temporánea. Toda la historia en el presente, 4. Recuperado de https://con-temporanea.inah.gob.mx/node/105

Semyonov, M. y Raijman, R. (2006). The raise of anti-foreigner sentiment in european societies, 1998-2000. American Sociological Review, 71(3), 426-449. http://doi.org/10.1177/000312240607100304 
Semyonov, M., Raijman, R., Yom, A. y Schmidt, P. (2004). Population size preceived threat, and exclusion: a multiple-indicators analysis of attitudes toward foreingers in Germany. Social Science Research, 33(4), 681-701. Recuperado de DOI 10.1016/j.ssresearch.2003.11.003

Silva, Y. (2014). Transmigración de centroamericanos por México: su vulnerabilidad y sus derechos humanos (Tesis doctoral en ciencias sociales con especialidad en estudios regionales). Tijuana: El Colegio de la Frontera Norte. Recuperado de https://www.colef.mx/posgrado/wp-content/uploads/2014/11/TESIS-SilvaQuir\%C3\%B3z-Yolanda-DCSER.pdf

Solé, C. (2010). Racial discrimination against foreingers in Spain. Journal of ethnic and migration studies, 21(1), 95-101. Recuperado de http://doi.org/10.1080.1369183X.1995.9976475

Sourial, N., Wolfson, C., Zhu, B., Quail, J., Fletcher, J., Karunanathan, S. y Bergman, H. (2010). Correspondence analysis is a useful tool to uncover the relationships among categorial variables. Journal of Clinical Epidemiology, 63(6), 638-646. Recuperado de DOI: 10.1016/j.jclinepi.2009.08.008

Tarrius, A. (2000). Leer, describir, interpretar las circulaciones migratorias: conveniencia de la noción de territorio circulatorio. Los nuevos hábitos de la identidad. Relaciones. Estudios de historia $y \quad$ sociedad. XXI(83), 38-66. Recuperado de http://www.redalyc.org/pdf/137/13708303.pdf

Terrón-Caro, T. y Monreal-Gimeno, M. (2014). Mujeres migrantes en tránsito en la Frontera Norte de México: motivaciones y expectativas. Papeles de población, 20(82), 137-166. Recuperado de https://www.redalyc.org/pdf/112/11232827007.pdf

Thomas, W. y Znaniecki, F. (2006). El campesino polaco en Europa y América. Madrid: Centro de Investigaciones Sociológicas y Boletín Oficial del Estado.

Tourliere, M. (18 noviembre de 2018). “¿No a la invasión!” claman tijuanenses contra caravana migrante. Proceso. Recuperado de https://www.proceso.com.mx/560082/no-a-la-invasionclaman-tijuanenses-contra-caravana-migrante-video

UN Refugee Agency. (2017). Aportes de las Américas . Pacto Mundial sobre refugiados. Ginebra: ONU. Recuperado de https://www.cepal.org/sites/default/files/presentations/michele_manca.pdf

United Nations, Departament of Economic and Social Affairs, population Division (2017). International Migration Report 2017: Highlights. New York: United Nations. Recuperado 
de

https://www.un.org/en/development/desa/population/migration/publications/migrationrep ort/docs/MigrationReport2017_Highlights.pdf

Varela, A. (2016). Luchas migrantes en contextos de tránsito migratorio, el caso del movimiento migrante centroamericano. REHMU-Revista Interdisciplinar da Mobilidade Humana, 24(48), 31-44. Recuperado de http://www.scielo.br/scielo.php?pid=S1980$\underline{85852016000300031 \& \text { script }=\text { sci_abstract\&tlng=es }}$

Vázquez, C. (2014). Migración y discriminación contra migrantes indígenas: el caso de las mujeres migrantes de la zona Metropolitana de Monterrey (Tesis de maestría en ciencias sociales con orientación en desarrollo sustentable). Monterrey: Universidad Autónoma de Nuevo León. Recuperado de http://cdigital.dgb.uanl.mx/te/1080259425.PDF

Vilches, M. (2011). Derecho(s) y política migratoria en México. Sonora y Guanajuato ente la migración. Trace, 60, 25-40. Recuperado de https://journals.openedition.org/trace/1730

Villamil, G. (22 octubre de 2018). El racismo y la xenofobia explotaron en las redes. Proceso. Recuperado de https://www.proceso.com.mx/556299/el-racismo-y-la-xenofobiaexplotaron-en-las-redes

Visauta, B. y Martori, J. (2003). Análisis estadístico con SPSS para Windows. Vol. II. Estadística multivariante. Madrid: Mc Graw Hill.

Wegrzynowska, K. (2015). La feminización de la migración mexicana en Estados Unidos. Revista del CESLA, 18, 313-336. Recuperado de https://www.redalyc.org/pdf/2433/243342822014.pdf

Willems, H. (1995). Right-wing extremism, racism or youth violence? Explaining violence against foreigners in Germany. Journal of Ethnic and Migration Studies, 21(4), 501-523. Recuperado de http://dx.doi.org/10.1080/1369183X.1995.9976509

Willers, S. (2016). Migración y violencia: las experiencias de mujeres migrantes centroamericanas en tránsito por México. Sociológica, 31(89), 163-195. Recuperado de http://www.redalyc.org/articulo.oa?id=305046937006

Wimmer, A. (1997). Explaining xenophobia and racism: A critical review of current research approaches. Ethnic and Racial Studies, 20(1), 17-41. Recuperado de: http://dx.doi.org/10.1080/01419870.1997.9993946 
InterSedes, $\mathbf{N}^{\circ}$ 42. Vol XX (2019). ISSN 2215-2458

Zamora-Kapoor, A., Kovincic, P. y Causey, C. (2013). Anti-foreigner sentiment: State of the art. Social Compass, 7(4), 303-313. Recuperado de https://www.ncbi.nlm.nih.gov/pmc/articles/PMC4350658/

Zepeda, R. y Rosen, J. (2016). Migración México-Estados Unidos: Implicaciones de seguridad. Revista de Ciencias Sociales, IV(154), 79-91. Recuperado de http://www.redalyc.org/pdf/153/15351156006.pdf 